\title{
Closing the circle of care: implementation of a web- based communication tool to improve emergency department discharge communication with family physicians
}

\author{
Cheryl Hunchak, MD, MPH*; David Tannenbaum, MD ${ }^{\dagger}$; Michael Roberts, MD ${ }^{\dagger}$; Thrushar Shah, BSc ${ }^{\ddagger}$; \\ Predrag Tisma, BSc ${ }^{\ddagger}$; Howard Ovens, MD*; Bjug Borgundvaag, PhD, MD*
}

\section{ABSTRACT}

Objective: Postdischarge emergency department (ED) communication with family physicians is often suboptimal and negatively impacts patient care. We designed and piloted an online notification system that electronically alerts family physicians of patient ED visits and provides access to visitspecific laboratory and diagnostic information.

Methods: Nine (of 10 invited) high-referring family physicians participated in this single ED pilot. A prepilot chart audit (30 patients from each family physician) determined the baseline rate of paper-based record transmission. A webbased communication portal was designed and piloted by the nine family physicians over 1 year. Participants provided usability feedback via focus groups and written surveys.

Results: Review of 270 patient charts in the prepilot phase revealed a $13 \%$ baseline rate of handwritten chart and a $44 \%$ rate of any information transfer between the ED and family physician offices following discharge. During the pilot, participant family physicians accrued 880 patient visits. Seven and two family physicians accessed online records for $74 \%$ and $12 \%$ of visits, respectively, an overall $60.7 \%$ of visits, corresponding to an overall absolute increase in receipt of patient ED visit information of $17 \%$. The postpilot survey found that $100 \%$ of family physicians reported that they were "often" or "always" aware of patient ED visits, used the portal "always" or "regularly" to access patients' health records online, and felt that the web portal contributed to improved actual and perceived continuity of patient care. Conclusion: Introduction of a web-based ED visit communication tool improved ED-family physician communication. The impact of this system on improved continuity of care, timeliness of follow-up, and reduced duplication of investigations and referrals requires additional study.

\section{RÉSUMÉ}

Objectif: La communication avec les médecins de famille après le renvoi des patients du service des urgences (SU) laisse souvent à désirer, et ce manque de relation a une incidence défavorable sur les soins. Nous avons conçu et mis à l'essai un outil de communication en ligne, qui informe, par voie électronique, les médecins de famille de la visite d'un de leurs patients au SU et qui leur donne accès aux résultats d'examens de laboratoire ou de diagnostic.

Méthode: Neuf médecins de famille (sur 10 invités) ayant un nombre élevé de malades dirigés ont participé à ce projet pilote mené dans un seul SU. Un examen des dossiers (30 patients pour chacun des médecins de famille) durant la phase préexpérimentale a permis de déterminer le volume de base de transmission des dossiers sur papier. Les neuf médecins de famille ont conçu un portail de communication sur le Web et I'ont mis à l'essai pendant un an. Les participants ont fait part de leurs observations sur la convivialité dans des groupes de réflexion et dans des enquêtes écrites.

Résultats: Une revue de 270 dossiers de patient durant la phase préexpérimentale a révélé un taux initial de dossiers rédigés à la main de $13 \%$ et un taux de communication de renseignements de $44 \%$ entre le SU et les cabinets des médecins de famille après le congé. Durant la phase expérimentale, les médecins de famille participants ont totalisé 880 visites de patients. Sept médecins de famille et deux autres ont consulté respectivement $74 \%$ et $12 \%$ des dossiers en ligne qui faisaient suite à des visites, soit un taux global de $60.7 \%$ des visites, ce qui représente une augmentation absolue générale de $17 \%$ de la communication de renseignements relatifs à des visites au SU. Dans I'enquête menée durant la phase postexpérimentale, $100 \%$ des médecins de famille ont indiqué qu'ils étaient "souvent" ou "toujours" au courant des visites de leurs

From the *Schwartz-Reisman Emergency Centre, †The Granovsky Gluskin Family Medicine Centre, and łInformation Technology, Mount Sinai Hospital, Toronto, ON.

Correspondence to: Dr. Cheryl Hunchak, Mount Sinai Hospital Joseph and Wolf Lebovic Health Complex, 60 Murray Street, Toronto, ON M5G 1X5; chunchak@gmail.com.

This article has been peer reviewed. 
patients au SU, qu'ils utilisaient "toujours" ou "périodiquement" le portail pour consulter les dossiers de leurs patients en ligne et qu'ils avaient l'impression que le portail Web avait contribué à l'amélioration de la continuité réelle ou perçue des soins aux patients.

Conclusions: La mise en place d'un outil de communication sur le Web, concernant les consultations au SU, ont amélioré les échanges entre les médecins de famille et le service en question. Toutefois, l'incidence de cet outil sur l'amélioration de la continuité des soins, la rapidité du suivi, et la réduction des demandes en double d'examens et de consultations en spécialité reste à approfondir.

Keywords: emergency care information systems, medical informatics application, patient discharge, primary care physicians
Consistent, timely communication of health record information between the emergency department (ED) and community family physicians is a necessity for the provision of high-quality primary patient care. Previous studies have demonstrated that family physicians typically lack real-time access to relevant clinical results following patients' ED visits. ${ }^{1-3}$ Multiple reasons account for this, including reliance on paper-based ED charting systems, related issues of handwritten record legibility, dependence on patients to hand-deliver records, and incomplete diagnostic information available at the time of ED discharge.

Physician-patient relationships, intraprofessional relationships, and overall patient care stand to benefit from improved hospital-community health record communication systems. ${ }^{1,4}$ Previous studies have suggested that a standardized electronic ED discharge system could improve communication. ${ }^{5-7}$ One Canadian study demonstrated that the introduction of an electronic standardized communication system significantly improved continuity of patient care following ED discharge, specifically contributing to a higher rate of information transfer and improved family physician knowledge of patient ED visits. ${ }^{7}$ Overall, the impact of ED-family physician electronic health record communication tools has been poorly studied.

Twelve years ago, the visionary Romanow Report stated that "the electronic transfer of information to and from the ED, the community family physician, and other institutions is vital." 8 The majority of surveyed Ontario ED chiefs indicated that patient health information would be better disseminated using electronic systems rather than standard paper-based methods. ${ }^{1}$ One survey of family physicians and community pediatricians found that the strongest indicators of interest in an electronic standardized communication system included having a personal email address at home and at work, office Internet access, and frequent email access. ${ }^{9}$ Our previous survey of community family physicians indicated that the majority of physicians do have office Internet and email access, and this access is nearly universal among physicians less than 50 years of age. ${ }^{3}$ Uptake of interphysician and physician-patient web-based electronic health record communication systems has lagged significantly behind uptake of email and Internet access in the general population. ${ }^{10-12}$ The reasons for this are multifaceted and have not been well studied. To date, the implementation results of only a single ED-family physician electronic communication system have been published. ${ }^{5}$

To improve continuity of care and relations between ED and community family physicians, we designed and piloted an automated web-based notification and health record communication tool. This novel tool alerts family physicians of a patient ED visit by email and provides real-time online, secure access to all visitspecific comprehensive laboratory and diagnostic test results (plans to digitize and include the written ED chart are under way). The purpose of this study was to develop and pilot the novel system, solicit physician feedback on usability, and compare family physician awareness of patients' ED visits pre- and postsystem implementation. Determination of the effect of this system on physician practice and patient care, although obviously very important, were beyond the scope of this pilot study.

\section{METHODS}

Ten high-referring community family physicians affiliated with a single hospital were invited to participate. All provided informed consent prior to participation. The web-based communication tool was built by experts in the hospital information technology (IT) department following a needs assessment survey of family physicians to determine the desirability, feasibility, and functionality of such a novel system. ${ }^{3}$ The communication tool consists of a standardized email 
notification message sent to family physicians at a registered email address within 24 hours of their patient's registration for an ED visit. On receiving the email notification, family physicians can $\log$ in using two-factor authentication approved by the hospital privacy board. This provides family physicians with access to all available health information pertaining to a specific patient's ED visit, including laboratory and diagnostic imaging results, electrocardiograms (ECGs), final discharge diagnosis, and discharge status (i.e., discharged home, admitted, or deceased). If microbiology or final diagnostic imaging reports are pending, this is visible to the family physician and can be accessed via the portal for a period of 3 months. At the time of this pilot, a scanned copy of the actual ED chart could not be incorporated into the available data. This work is under way, and a digital copy of the chart will be available through the portal in the near future. All results and reports are printable from the portal platform.

This pilot implementation study consisted of three components: 1) a prepilot chart audit to assess how often participating family physicians were aware of their patient visits to the ED at baseline, 2) online monitoring of family physician web portal use during the pilot phase, and 3) a postpilot quantitative (written survey) and qualitative (focus group) assessment of family physicians' experience using the web portal.

The prepilot chart audit consisted of a review of 300 charts from the 10 family physicians' offices. Chart audits were conducted by a single reviewer using a standardized form. The 30 most recent patient visits to the ED for each physician were audited. ED hospital visit records were compared to family physician office charts for the same patient and examined for references to the ED visit in the clinical notes and/or the presence of ED records and results in patient charts. We categorized these results as follows: if a copy of the handwritten ED record was found in the chart, this was deemed "ED written record" transfer of information to the family physician. If there was any reference to an $\mathrm{ED}$ visit found in the family physician clinical notes or any other paper copy of a hospital record (e.g., radiograph or microbiology reports, ECGs, etc.), this was deemed "any" information transfer.

The web portal was launched with exclusive access provided to participating family physicians in March 2011. User data were collected regarding patient ED visits accrued over a 1-year period from March 2011 to March 2012. The following measures were identified to monitor web portal use: 1) number of unique patient ED visits per family physician, 2) percentage of ED visits where patient consent was granted to release health information via the web portal, and 3 ) number of times patient records were accessed online by family physicians following a notification message.

In September 2011, after 235 patient ED visits were accrued, users completed a standardized written survey consisting of 12 questions to assess the web portal's utility and the impact it had on their daily practice and patient care. The family physicians also participated in focus groups that inquired about ease of web portal use, perceived enthusiasm among their peers for wider implementation, future desired functionalities, and the impact of the web portal on patient care. Focus groups were conducted by a single investigator and consisted of a series of 10 structured questions. The qualitative results were compiled and analyzed for recurring themes.

This study was approved by the research ethics board of Mount Sinai Hospital. Statistical analysis was completed using SAS 9.3 for Windows (SAS Institute, Cary, NC). To compare the pre- and poststudy rates of family physician access to post-ED visit health record information, logistic regression was used using the generalized estimation equation (GEE) method to adjust for repeated measures.

\section{RESULTS}

One of the 10 community family physicians left their practice at the study outset and declined to allow access their charts. Nine family physicians participated in the study. The prepilot chart audit was completed for 270 discrete ED patient encounters. Seventeen patient charts were missing at the time of the audit, and 253 family physician charts were audited. Only 34 (13.4\%) office charts contained a written copy of the ED chart. An additional 79 (31.2\%) charts contained any information related to the patients' ED visit. In total, fewer than half $(44 \% ; n=112)$ of the audited charts contained any record of the patient's visit to the ED. Table 1 details the frequency of tests ordered during ED visits, the frequency with which these test results were evident in the family physician charts, and the degree of family physician awareness of such results.

During the year-long pilot phase, the family physicians accrued 880 patient visits to the ED (Table 2). Of these, 858 (97.5\%) patients visiting the 


\begin{tabular}{|c|c|c|c|}
\hline \multirow[t]{2}{*}{ Test type ( $n=253$ patient charts) } & \multirow{2}{*}{$\begin{array}{c}\text { Number ordered } \\
n(\%)^{*}\end{array}$} & \multirow{2}{*}{$\begin{array}{c}\text { Report on FP chart } \\
\qquad n(\%)^{\dagger}\end{array}$} & \multirow{2}{*}{$\begin{array}{c}\text { FP aware } \\
n(\%)^{\dagger}\end{array}$} \\
\hline & & & \\
\hline Radiograph & $80(31.6)$ & $6(7.5)$ & $11(13.7)$ \\
\hline Sonogram & $14(5.5)$ & $4(28.6)$ & $5(35.7)$ \\
\hline CT scan & $24(9.4)$ & $5(20.8)$ & $8(33.3)$ \\
\hline ECG & $67(26.4)$ & $7(10.4)$ & $10(14.9)$ \\
\hline Abnormal imaging result & $77(65.2)^{\ddagger}$ & & $11(14.3)$ \\
\hline Routine bloodwork & $148(54.8)$ & $24(16.2)$ & $28(18.9)$ \\
\hline Other bloodwork & $132(48.8)$ & $20(15.1)$ & $23(17.4)$ \\
\hline Abnormal bloodwork & $115(77.7)^{\S}$ & & $7(6.0)$ \\
\hline C\&S & $41(15.1)$ & $3(7.3)$ & $3(7.3)$ \\
\hline \multicolumn{4}{|c|}{ 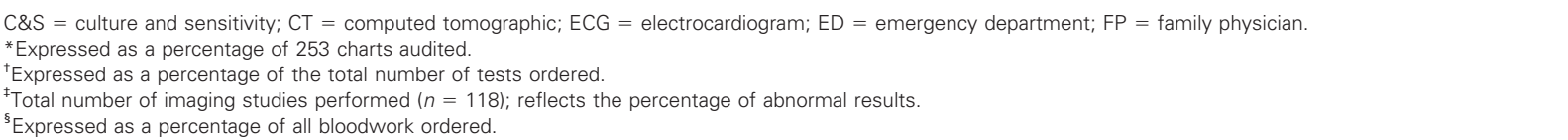 } \\
\hline
\end{tabular}

ED consented to the electronic release of ED records to their family physicians. For each of these visits, family physicians received an email notification of the patient's ED visit $100 \%$ of the time (thus, they were $100 \%$ aware when their patient had been in the ED, regardless of whether or not they accessed the electronic record). This clearly represents an important increase in family physician awareness of patient visits. Specific patient records were subsequently accessed online by family physicians $60.7 \%$ of the time. Of the patient visits accessed online, nearly one-quarter of visits $(23.6 \%)$ were accessed by family physicians more than once.

We observed a bimodal distribution of physicians accessing the portal, with most physicians using the system extensively and two physicians accessing the system on a limited basis. The "heavy-user" group accrued 665 patient visits and accessed the system 495 (74.4\%) times, whereas the "light-user" group accrued 215 visits but accessed the system only 26 (12\%) times. By virtue of the fact that all participating family physicians automatically received email notification of their patients' ED visits in real time, all family physicians were aware of such visits $100 \%$ of the time, signifying an increase in overall awareness of as much as $56 \%$ (44\% preimplementation; $100 \%$ postimplementation). Using physician system access as a proxy, we found a $17 \%$ absolute increase in physician access to patient ED visit health records postimplementation (44\% preimplementation, $61 \%$ postimplementation). Although the nature of this small pilot study prevented this from reaching statistical significance $(p=0.23)$, this was felt to be a clinically meaningful outcome.

The postpilot survey was completed by all nine participating family physicians. During the pilot study, $100 \%$ of family physicians were either "always" (89\%) or "often" (11\%) aware of their patients' ED visits, and $100 \%$ used the portal "always" (44\%) or "regularly" $(56 \%)$ to access their patients' health records online. Two-thirds $(67 \%)$ of family physicians reported that the information provided by the web portal "often" helped optimize patient management. Overall, the perceived impact of the web portal on patient care was reported by $100 \%$ of participants as moderate $(67 \%)$ or

Table 2. Web portal user data (1 year)

\begin{tabular}{|c|c|c|c|c|}
\hline $\begin{array}{l}\text { Total number of visits } \\
\text { accessed }\end{array}$ & $\begin{array}{l}\text { Visits accessed } \\
\text { once }\end{array}$ & $\begin{array}{c}\text { Visits accessed } \geq 2 \\
\text { times }\end{array}$ & $\begin{array}{l}\text { Visits with patient consent } \\
\text { to release information }\end{array}$ & $\begin{array}{c}\text { Total number of ED patient } \\
\text { visits }\end{array}$ \\
\hline$n(\%)$ & $n(\%)$ & $n(\%)$ & $n(\%)$ & \\
\hline $521(60.7)$ & 398 (76.3) & $123(23.6)$ & $858(97.5)$ & 880 \\
\hline
\end{tabular}


high (33\%). There was a strong reported preference for receiving post-ED visit notifications by email rather than by fax (78\%) after using the web portal system. Two-thirds of family physicians were in favour of their patients having electronic access to ED health record information (Table 3).

The postpilot focus group sessions revealed that the single greatest way the web portal changed family physicians' practice was in impressing patients, family members, and administrative staff with timely knowledge of ED visits, regardless of whether specific follow-up was required. Family physicians felt that they were able to be more proactive in contacting patients to book reassessment appointments and acknowledge the ED visit, which improved both perceived and actual continuity of care. Family physicians subjectively felt that the web communication tool reduced unnecessary duplication of investigations and referrals, although this was not tested formally. There were no perceived barriers to rolling out access to a greater number of community family physicians. The anticipated level of enthusiasm among their peers for access to the web communication tool was high.

\section{DISCUSSION}

This pilot study demonstrates a proof of concept in designing and piloting a novel automated web-based communication tool to notify family physicians of patient ED visits and allow secure access to hospital ED health record results. Prior to implementation of this tool, we observed an unacceptably low rate of paper-based health record transfer between the ED and family physicians, which was consistent with previous studies. ${ }^{1,4}$ The nature of this pilot study prevents us from making hard statistical conclusions regarding how this system affected patient care (e.g., fewer tests, fewer referrals, expedited follow-up for certain conditions, etc). There seems little doubt that our system improved ED-family physician communication. The automated email notification feature ensured that family physicians were aware of patient ED visits $100 \%$ of the time, with individual health records being accessed $61 \%$ of the time, representing a minimum absolute increase in health record transfer of $17 \%$.

Our prepilot chart audit documented some evidence of patients' ED visits in family physician office charts $44 \%$ of the time. This likely represents an overestimate of baseline health record transfer rates because we considered "any" note in the chart showing evidence of an ED visit to represent transmission of medical records and a copy of the ED handwritten record as evidence of "as complete as possible" information transfer. The ideal complete transmission of medical information would include a legible copy of the ED record (including chief complaint, discharge diagnosis, clinical examination notes, and prescription information) in addition to all the information available

Table 3. Postpilot experience and attitudes toward web-based ED-FP communication

\begin{tabular}{|c|c|c|}
\hline & Response & $\%(n=9)$ \\
\hline \multirow[t]{2}{*}{ Awareness of patient ED visits } & Always & 89 \\
\hline & Often & 11 \\
\hline \multirow[t]{2}{*}{ Frequency of web portal use to access ED health records online } & Always & 44 \\
\hline & Regularly & 56 \\
\hline Adequacy of 3-month time period for online availability of ED health records & Sufficient & 100 \\
\hline \multirow{4}{*}{ Ideal length of time for secure online availability of ED health records } & As long as possible & 44 \\
\hline & $8 w k$ & 11 \\
\hline & 4 wk & 33 \\
\hline & $2 w k$ & 11 \\
\hline \multirow[t]{2}{*}{ Preference for mode of notification of patient ED visits } & Email & 78 \\
\hline & Fax & 22 \\
\hline \multirow[t]{3}{*}{ Perceived impact of access to online ED visit information on patient management } & Always & 11 \\
\hline & Often & 67 \\
\hline & Sometimes & 22 \\
\hline \multirow[t]{2}{*}{ Impact of web portal on perceived ability to provide quality patient care } & High & 33 \\
\hline & Moderate & 67 \\
\hline
\end{tabular}


through our portal. Taken together, this information would facilitate follow-up appointment timing and/or follow-up outpatient test ordering by family physicians.

In reality, the handwritten ED record is a carbon copy of the ED physician's clinical notes and does not consistently contain laboratory or diagnostic findings or other results generated during the ED visit. At best, this written record represents a limited history of the patient ED encounter, if legible. By contrast, family physicians accessing the electronic portal had access to the complete health record visit, including results not available at the time of patient discharge. Indeed, 24\% of patient records were accessed multiple times during our study, suggesting that pending information with the capacity to influence care was considered important and helpful. Qualitatively, postpilot family physician user feedback was extremely positive and overwhelmingly in favour of wider rollout to community family physicians.

During the pilot implementation phase, family physicians accessed online health records following email notification of a patient's ED visit $60.7 \%$ of the time. The reasons for less than $100 \%$ access are a point of speculation and include several considerations. First, a minority of family physicians may simply not have been interested in adopting the electronic portal. With the introduction of any new technology, the phenomenon of early and late adaptors can be expected, and the light-user group may represent late adaptors. In the postpilot study phase, both light-user family physicians indicated that they liked and used the web portal and did not identify any major shortcomings with the system. Second, family physicians may already be aware of certain patients presenting to the ED for known conditions and may be facilitating patients' ED visits. This could be for well-defined problems that do not require results follow-up, such as a newly diagnosed fracture requiring a cast or a patient with advanced cancer requiring inpatient pain management.

Although this proof-of-concept study was not powered to evaluate the impact of the web portal on patient care, timely electronic communication of ED records to family physicians has the potential to reduce unnecessary duplication of tests and referrals, reduce gaps in continuity of care, improve patient and family perceptions of continuity of care, and enhance "circle of care" relationships between hospital-based and community physicians. Although a single study found that resource use was not significantly reduced by the implementation of a standardized ED-family physician electronic communication system, ${ }^{5}$ there is a pressing need for further research in this area. The communication tool piloted in this study is innovative in proactively notifying family physicians of patient ED visits to alert them to changes in the patient's medical status. Family physician notification of patient ED visits for minor, self-limited, or chronic conditions offers an opportunity for family physicians to be aware of their patients' ED use, which may provide valuable information that can positively impact patient care pertaining to substance abuse, opioid dependence, mental illness, and other conditions that family physicians may not be aware of. That $97 \%$ of patients consented to having their visit information sent to their family physician suggests that patients are in favour of this method of communicating with family physicians.

The use of email as a communication tool between hospitals and community physicians has been underused. ${ }^{10,11} \mathrm{We}$ are aware of only one other hospital in the Greater Toronto Area using an electronic notification system to convey $\mathrm{ED}$ visit information to family physicians. ${ }^{13}$ Several other electronic health record communication initiatives are under way but have not been formally studied. It is possible that cost is one consideration preventing the development of IT infrastructure for such applications. Our project budgeted C\$75,000 for the development, implementation, and maintenance of our web portal. It remains to be seen if the development and implementation of such systems can be shown to be cost-effective when balanced against reduced duplication of tests and other possible benefits. The cost of developing our system was well worth the expense and will lead to improved care. Partnerships with hospital IT departments will be essential as the particulars of each hospital emergency medical record system are unique. If physicians favour patients having access to their own electronic ED health records, as our studies suggest, ${ }^{3}$ an opportunity exists to increase portability of patient access to their own records, enabling delivery of key information to care providers outside a specific hospital's catchment area. ${ }^{13}$ Because a substantial number of patients visiting EDs report not having a family physician, the provision of electronic ED records directly to patients has the potential to improve care for this population. 
Our study has several limitations. Limited data points for each phase of this study may not reflect the experience, perceptions, or opinions of a broader community of family physicians. These positive results quantified among nine high-referring family physicians provide proof of concept that wider implementation and further research are warranted. Although the pilot study officially concluded in March 2012, web portal access remains open to pilot users, and subsequent data indicate that the web portal continues to be used consistently. This strongly suggests that it has become a valuable communication tool adopted by participating family physicians well beyond the purposes of this pilot study.

With respect to the prepilot chart audit, there may be benign reasons why a hard copy of an ED visit record does not reach a family physician's office. Some patients visit the ED for self-limited minor conditions that may not mandate specific family physician followup. However, our postpilot study findings challenge the notion that ED health record information for minor self-limited conditions is unnecessary to communicate to family physicians given that several family physicians accessed patient records more than $90 \%$ of the time. Additionally, family physician and patient perceptions of exemplary continuity of care were engendered by family physician awareness that their patient had been in the ED, regardless of whether specific follow-up was required.

Broader study limitations pertain to the web communication tool design itself. At present, the information available for electronic transfer is limited by hospitalbased emergency medical record (EMR) systems and will vary between hospitals. Understandably, pilot participants requested that discharge instructions, outpatient referrals, and medication changes also be included in the web portal system, which are currently not part of the hospital-based EMR. These sentiments have been shared by family physicians in earlier studies, ${ }^{14,15}$ and although including a scanned version of the ED records will address some of these issues, others will require increased sophistication of evolving hospital EMR systems, which takes time.

\section{CONCLUSIONS}

This innovative and important pilot study demonstrates an overall absolute increase in real-time family physician awareness of patient ED visits and access to electronic health record information, and shows significant promise for wider rollout and expanding applications. As web-based health record communication tools emerge, important questions remain. Patient demand for online access to portable electronic health records is unquantified and complicated by privacy issues. Further research is needed to assess the uptake of this particular ED visit communication tool among a larger, more heterogeneous group of family physicians and to determine its applicability at other hospitals. Physicians, patients, and IT specialists all have integral roles to play in the continued development and implementation of web-based health communication tools, with the common goal of closing the circle of communication between shared health care providers and improving continuity of care.

Competing interests: None declared.

\section{REFERENCES}

1. Stiell AP, Forster AJ, Stiell IG, et al. Maintaining continuity of care: a look at the quality of communication between Ontario emergency departments and community physicians. CFEM 2005;7:155-61.

2. Sherry M, Edmunds S, Touquet R. The reliability of patients in delivering their letter from the hospital accident and emergency department to their general practitioner. Arch Emerg Med 1985;2:161-4, doi:10.1136/emj.2.3.161.

3. Hunchak C, Patel A, Teo A, et al. Development of a novel web-based tool to improve emergency department discharge communication with general practitioners: a needs assessment survey. Open Emer Med $\mathcal{F}$ 2013;5:37-44.

4. Stiell A, Forster AJ, Stiell IG, et al. Prevalence of information gaps in the emergency department and the effect on patient outcomes. CMAF 2003;169:1023-8.

5. Lang E, Afilalo M, Vandal AC, et al. Impact of an electronic link between the emergency department and family physicians: a randomized controlled trial. CMA7 2006;174:313-8, doi: $10.1503 / \mathrm{cmaj} .050698$.

6. Wass AR, Illingworth RN. What information do general practitioners want about accident and emergency patients? 7 Accid Emerg Med 1996;13:406-8, doi:10.1136/emj.13.6.406.

7. Afilalo M, Lang E, Leger R, et al. Impact of a standardized communication system on continuity of care between family physicians and the emergency department. CFEM 2007;9: 79-86.

8. Commission on the Future of Health Care in Canada. Building on values. The future of bealth care in Canada - final report. November 28, 2002. Available at: http://www.hcsg.gc. ca/english/pdf/romanow/pdfs/HCC_Final_Report.pdf (accessed December 6, 2012).

9. Goldman RD. Community physicians' attitudes towards electronic follow-up after an emergency department visit. Clin Pediatr 2005;44:305-10, doi:10.1177/000992280504400 $\underline{404}$. 
10. Moyer CA, Stern DT, Dobias KS, et al. Bridging the electronic divide: patient and provider perspectives on email communication in primary care. Am 7 Managed Care 2002;8:427-33.

11. Gaster B, Knight CL, DeWitt DE, et al. Physicians' use of and attitudes toward electronic mail for patient communication. 7 Gen Intern Med 2003;18:385-9, doi:10.1046/j.15251497.2003.20627.x.

12. Tenforde M, Jain A, Hickner J. The value of personal health records for chronic disease management: what do we know? Fam Med 2011;43:351-4.
13. Yau GL, Williams AS, Brown JB. Family physicians' perspectives on personal health records. Can Fam Physician 2011;57:e178-84.

14. Van Walraven C, Rokosh E. What is necessary for highquality discharge summaries? Am 7 Med Qual 1999;14:160-9, doi:10.1177/106286069901400403.

15. Wass AR, Illingworth RN. What information do general practitioners want about accident and emergency patients? $\mathcal{F}$ Accid Emerg Med 1996;13:406-8, doi:10.1136/emj.13. $\underline{6.406 .}$ 